\title{
KIAT MAHASISWA BERKOMUNIKASI DIDALAM BAHASA INGGRIS PASKA PENDEKATAN FRESHNESS DAN ENTHUSIASM
}

Oleh: Doddy Rusmono

Program Studi Perpustakaan dan Informasi

Universitas Pendidikan Indonesia

Email : drusmono@yahoo.co.id

\begin{abstract}
Through DIMBI (Diskusi Ilmiah Mahasiswa Berbahasa Inggris - Student's English Discussion) some can be drawn that learners (i.e. Students) want to have their messages accepted in a proper way by the receiver in the target language. By merely integrating vocabulary and grammar to communicate, the meaning of the expression could not reach the intended receiver and might end up with being incomprehensive on his part. Elelments of culture are neede to make other people understand what you are trying to say, especially when the one you are talking to is a native speaker of English language. Learners are in the situation in which English fall into the category of a foreign, and not English as a second language. When learning English as a second language takes place, the learners are involved in the language in their daily life ectivities while learning English as a foreign language as the case in Indonesia, acquisition and usage depend on and are restricted to learning structures as designed for classroom mode with its various impacts. However little any attempts made by the learners, appreciation and good points of view must emerge for the sake of skill developments. Ways of exploring with tricks by the learners everytime they try to communicate in English with a number of mistakesn needs to be ameliorated in such a way that hopes for betterments live a good endeavour. Approach in the light of teacher demeanor brings with it a positive impact. The approach generates freshness and enthusiasm as well and thus encouraging the learners to express with confidencde regardless of possible inaccuracies in their various forms.
\end{abstract}

Keywords: vocabulary, grammar points, communication, culture, target language.

\begin{abstract}
Abstrak
Melalui DIMBI (Diskusi Ilmiah Mahasiswa Berbahasa Inggris) terperoleh simpulan bahwa para pembelajar (baca: Mahasiswa) ingin agar pesan yang mereka komunikasikan dapat berterima. Dengan menggabungkan kosa-kata dan gramatika saja pesan yang mereka sampaikan sebagai penutur belum cukup untuk memenuhi keberterimaan oleh penerima pesan pada bahasa sasaran (Bahasa Inggris). Diperlukan unsur kultur untuk mencapai bahasa sasaran. Unsur kultur akan sangat menentukan makna yang ditangkap oleh penerima pesan, terutama bilamana penerima pesan tadi adalah penutur asli (native speaker). Pembelajar berada dalam situasi yang dikategorikan Bahasa Inggris sebagai Bahasa Asing (English As A Foreign Language)
\end{abstract}


EduLib, Vol 1, No.1 Mei 2013

\begin{abstract}
, bukan sebagai Bahasa Kedua (English As A Second Language). Ketika bergagas melalui ujaran didalam Bahasa Inggris sebagai bahasa kedua, pembelajar dilibatkan dengan bahasa ini didalam kehidupan sehari-hari mereka sedangkan pembelajaran Bahasa Inggris sebagai bahasa asing seperti misalnya di Indonesia, perolehan dan penggunaan Bahasa Inggris tergantung dan terbatas pada rancangan belajar di ruang kelas dengan segala dampak penyertanya. Upaya sekecil apapun oleh pembelajar harus dilihat dari segi positifnya untuk kemudian dicarikan cara pengembangannya. Kiat penuh kekeliruan sekalipun perlu dihidupkan agar komunikasi tetap berlangsung lancar dan berterima. Pendekatan melalui teacher demeanor yang menyegarkan dan penuh semangat membawa dampak positif bagi pembelajar berupa keberanian berekspresi, terlepas dari ketidakpasan disana-sini.
\end{abstract}

Kata kunci: kosa kata, gramatika, komunikasi, kultur, bahasa sasaran.

A. PENDAHULUAN

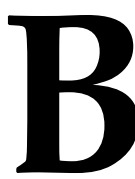

erbekal keyakinan minimal berkompetensi didalam penggunaan Bahasa Inggris

(B.Ing.) untuk beradaptasi dengan iklim asing berkomunikasi, Mahasiswa sebagai pembelajar seyogianya memiliki kosa kata cukup dan mengetahui serba sedikit mengenai gramatika seperti misalnya rumusan $9 \mathrm{BP}+3(\mathrm{Cd}, \mathrm{Cx}, \mathrm{Cdx})$ dan $\mathrm{PoS}$ untuk mengawalinya. Selain itu, pengetahuan Mahasiswa tentang kultur bahasa sasaran memang berperan besar. Seperti diungkapkan Cakir (2006), "Most frequently confronted that students to a great extend know the rules of language, but are not knowledgeable enough about the target culture."

Kedua bahasa, Bahasa Indonesia (bahasa sumber, bahasa ibu) dan Bahasa Inggris (bahasa sasaran, bahasa asing), merupakan alat berkomunikasi dengan dua arus yang paralel sehingga kesadaran akan adanya perbedaan sosiokultural dan sosiolinguistik diperlukan ketika kegiatan berkomunikasi berlangsung. Didalam kesenjangan kultural bahasa ibu penutur asli dengan bahasa sasaran seharusnya tersisipkan penyempit kesenjangan kultur ketika komunikasi berlangsung. Terbukti sudah bahwa kosa kata memadai bukan satu-satunya alat untuk 
mengekspresikan diri melainkan juga bagaimana lawan bicara disodori makna pada bahasa sasaran bermuatan kultur. Bukti perbedaan bahasa bermuatan kultur adalah bahwa beberapa bahasa mempunyai kata-kata khusus untuk beberapa konsep sedangkan bahasa-bahasa lainnya perlu menggunakan beberapa kata untuk menyampaikan suatu konsep khusus (Eastwood, 1982; Allyn, 2013).

Didalam pembelajaran B.Ing. sebagai bahasa kedua (English As A Second Language) seperti misalnya di Singapura, pembelajar dilibatkan dengan bahasa ini didalam kehidupan sehari-hari mereka sedangkan pembelajaran B.Ing. sebagai bahasa asing (English As A Foreign Language) seperti misalnya di Indonesia, perolehan dan penggunaan B.Ing. tergantung dan terbatas pada rancangan belajar di ruang kelas dengan segala dampak penyertanya (Macau, 2003). Menurut Fodor (1974) pandangan yang umum dan masuk akal adalah bahwa ketika penutur (baca: para Mahasiswa) menyampaikan gagasannya didalam B.Ing., mereka ingin agar apa yang ada didalam benaknya tersampaikan dengan benar, dan bukan dengan "benar" karena terkendala oleh kekurangtahuan kultural. Memang, salah satu dari delapan kelemahan bahasa menurut Hidayat (2009) adalah bahwa ketika bahasa digunakan oleh penggunanya, seringkali terjadi kecenderungan emosional dan tidak terarah. Beberapa Guru, Instruktur, ataupun Dosen B. Ing., seringkali menyiasati pembelajaran B.Ing. sebagai bahasa asing melalui pendekatan yang oleh Parsons (2013) disebut Teacher Demeanor yaitu pendekatan yang disertai ulasan senyum berulangkali dan hati yang tulus penuh pengertian atas berbagai ketidakpasan yang ditampilkan secara tidak sengaja oleh para pembelajar. Bahkan, ada juga sebagian pengajar B.Ing. yang mencoba mengadopsi gaya badut agar 
EduLib, Vol 1, No.1 Mei 2013

suasana pengajaran di kelas menjadi hidup dan bersahabat sehingga menyejukkan hati peserta ajar dengan berbagai keterbatasan kulturalnya. Sekaitan dengan gejala ini, ucapan Munoz-Bazds (2005) “The funny teacher is not a clown figure. He is a serious, conscientious professional who believes in the meaningfulness and effectiveness of having fun while learning." menjadi sarat makna, dan mengarah kepada pencerahan pembelajaran.

\section{Para Mahasiwa yang} mencermati kuliah B.Ing. di kelas kadang-kadang memberikan kesan bahwa mereka terkekang oleh kesulitan-kesulitan yang terselipkan didalam materi ajar untuk bahasa asing ini. Karena penguasaan bahasa asing memerlukan pengembangan keempat ketrampilan "erweeles" RWLS (Reading, Writing, Listening, Speaking), mereka harus memperolehi informasi linguistik dan semantik yang memang senantiasa berkelanjutan berkembang. Sehingga, pengajar B.Ing. selaku fasilitator perlu mengetahui cara melibatkan para pembelajarnya kedalam suasana yang mengundang minat bergagas. Dalam hal ini, humor (baca: lelucon/kejenakaan) merupakan media yang efektif karena dengan cara ini diharapkan muncul kreativitas didalam bahasa sasaran sekaligus membantu menciptakan lingkungan belajar yang optimal. Ketika para Mahasiswa terpingkal tawanya dan terhibur hatinya selama kegiatan belajar di kelas, maka pengajar sebenarnya sedang berada dalam proses pencapaian tujuannya: memberanikan dan memotivasi Mahasiswa untuk dapat berkomunikasi didalam bahasa sasaran.

Salah satu media yang dapat digunakan pada kelas bahasa asing ini adalah dengan cara menambahkan humor tentang kekeliruan tipikal gramatika, seperti misalnya kekeliruan pengucapan (mispronunciation). Jones (1978) mengatakan No two people pronounce 
exactly alike. Menurutnya, perbedaan antar perorangan tadi timbul dari beragam sebab, seperti misalnya kedaerahan (locality), pengaruh awal, dan kehidupan sosial masyarakat sekitar. Belum lagi keganjilan individual yang sangat sulit atau mustahil dipersoalkan. Unsur kekeliruan pengucapan sangat kental diwarnai oleh logat kedaerahan, seperti misalnya pengucapan huruf " $F$ " menjadi "P" atau sebaliknya yang sebenarnya huruf " $\mathrm{P}$ " tetapi diucapkan "F" pada kedaerahan Jawa Barat. Kejenakaan yang sering memicu tawa terbahak-bahak misalnya adalah ketika Mahasiswa berlogat kental Jawa Barat harus mengucapkan kalimat ini dengan benar: It's very difficult to park my car in the parking lot. Persis seperti Mahasiswa lainnya yang berkedaerahan sama mengucapkan nama seorang artis Novia Kolopaking, maka yang terdengar adalah seperti ini Nopia Kolofaking. Humor menyisipkan bingkai kultural kedalam bahasa sasaran dengan cara menyuguhkan nada (logat kental), ekspresi bergagas, dan konteks kepada bahan ajar. Unsur kekeliruan gramatik dapat dicontohkan ketika salah seorang dari sekelompok Mahasiswi merentangkan tangannya dari jarak agak jauh untuk menyambut sekelompok Mahasiswi lainnya sambil berteriak "Where are you?" Maksudnya pasti "Kemana saja kalian selama ini?" Padahal, sang Mahasiswi tadi tahu dan sadar bahwa teman-temannya yang disapa tadi jelas terlihat dan mewujud didepan matanya. Mengapa bertanya "Dimana kalian?" Seolah-olah dia tidak melihat yang disapa, seperti pada permainan petak-umpet. Sebenarnya, sapaan tadi seharusnya adalah "Where have you been?" Satu lagi, dialog antara Dosen dengan Mahasiswa di ruang kelas, yang cukup baik untuk dijadikan contoh perkeliruan. Mahasiswa yang ini menggunakan kosa kata yang tidak disarankan untuk dialihbahasakan guna menyampaikan 
EduLib, Vol 1, No.1 Mei 2013

pesan: "The name is also effort, Sir." Maksudnya mungkin "Namanya juga usaha, Pak." Selain sudah terjadi penginggrisan Bahasa Indonesia dengan menyimpangi kaidah penerjemahan, bagi sang Pengajar ungkapan tadi dapat mengundang rasa geli. Itulah sebabnya mengapa Balasko (2006) didalam Rusmono (2010) mengatakan "Students seem to find it difficult to compare and transmit two different systems of language and culture simultaneously." Didalam kelas, dialog menggunakan B.Ing. memang seyogiyanya diperuntukkan bagi pembelajar yang sudah pernah belajar bahasa internasional ini tetapi belum sempat mempraktekkannya, dan topik yang diangkat harus bersifat kontroversial agar pembelajar terpancing untuk masuk ke suasana debat dengan sengit (Moore, 1982; Franklin, 1990), walaupun sang fasilitator harus menelan Panadol ataupun Paramex seusai sesi berbobot 3 sks di kelas.
Sebagai pengajar, menghindari komentar yang tidak berdampak positif bagi pembelajar merupakan keharusan (Gandi, 2009). Artinya, pembelajar harus dibebaskan dari pemikulan beban ganda: beban linguistik dan beban mental. Jadi, kalau tidak akan berguna atau bahkan berkemungkinan menyakitkan hati, lebih baik tidak memberikan komentar sama sekali. Menjauhkan para pembelajar dari komentarkomentar masa lalu yang mungkin saja pernah dialami dalam hidupnya ketika belajar B.Ing. pada jenjang pendidikan formal di tiga atau empat tahun pertama - masa ketika untuk pertama kalinya struktur gramatika dan fungsi komunikasi pada umumnya didapatkan dari sekolah merupakan ide brilian (Eastwood, 1982).

$$
\text { Bagi pembelajar, }
$$
memberdayakan diri melalui berbagai kesempatan belajar merupakan suatu keniscayaan. Penuturan Allen (1974) berikut ini bersifat fundamental: 
The following general yang seyogianya sudah terkuasai. principles are self-evident:

1. All students want to speak, write and read the normal accepted English today

2. This commonly be achieved by constant practice of existing forms, with some rational explanation of the grammatical devices employed, whenever this is possible.

Pada dasarnya memang para Mahasiswa ingin B.Ing. mereka pas dan berterima ketika berkomunikasi. Namun untuk sekedar menginggriskan B.Ing. mereka, kesempatan mempraktekkan bentukbentuk yang hidup dan dipakai didalam berkomunikasi secara berkelanjutan agak langka, atau, kesempatan melihat peluang untuk berkegiatan kominikatif-interaktif agak terkendala oleh iklim lingkungan. Apalagi, ketika praktek tadi perlu dikawal oleh penjelasan yang rasional tentang formulaformula gramatik yang digunakan. Belum lagi jumlah kosa kata minimal 
EduLib, Vol 1, No.1 Mei 2013

Untuk mengawali kiat, Mahasiswa diinspirasi oleh rumusan $9 \mathrm{BP}+3(\mathrm{Cd}, \mathrm{Cx}, \mathrm{Cdx})$ dan PoS yang merupakan singkatan, agar mudah diingat. Kepanjangan singkatan tadi adalah Sembilan Pola Dasar Ujaran Sederhana ditambah tiga kalimat majemuk (Compound, Complex, Compound Complex) dan Part of Speech. Melalui semacam ketrampilan memadukan semua unsur ini, Mahasiswa dapat beranalogi dengan rumusan yang biasanya digunakan didalam Ilmu Kimia karena bahasa mempunyai sedikit kemiripan dengan disiplin Ilmu Kimia, karena bahasa juga bekerja dengan aksioma. Melalui pembentukan kata jadian (derivatives), misalnya, sebuah kata akar dapat ditambahi awalan (prefix) ataupun akhiran (suffix) sehingga terbentuk kata baru untuk digunakan pada kalimat dengan konteks dan struktur yang berbeda. Kata clean dapat diperkayakan menjadi clean, cleanly, cleanness, cleanliness, cleaner, cleanse, dan cleanser. Berarti, dari 1 kata dapat menjadi 8 kata, yang kelak berguna untuk menyampaikan pesan melalui kalimat-kalimat yang berbeda struktur gramatikanya namun tetap sama artinya. Jika harus “disejajarkan” dengan aksioma pada Ilmu Kimia, menurut kamus, kata jadian adalah suatu zat yang secara struktur dihubungkan dengan zat lain yang menurut teori dapat diperoleh dari zat tadi dan sering digunakan untuk memverifikasi struktur dari zat asal. Masih ada cara lain untuk pengayaan kosa kata yaitu dengan menggunakan cara mempopulerkan kata yang "kurang populer" melalui 
KW\&RW (Key Word and Related

Word)- kata kunci dan kata lain dengan arti yang mirip tetapi "kurang populer" (baca: canggih) dimana satu kata dihubungkan dengan kata-kata lain. Kata teman, misalnya, atau friend, mempunyai RW sebanyak 5 kata yaitu ally, companion, crony, acquaintance, dan confidant. Ke 5 kata terakhir ini tidak sepopuler kata friend, dan tidak banyak diketahui oleh khususnya pembelajar pemula (beginners). Untuk pembelajar, faktor kesabaran dan ketabahan sangat diperlukan didalam menghidupkan semangat penuh memperolehi kata-kata baru, misalnya dengan seringsering berkonsultasi pada kamus. Sehingga, kegiatan individual untuk memperkaya diri dengan mengoleksi katakata baru dapat terwujud. Secar ringkas, hanya dua hal yang dapat menjadikan seorang pembelajar tangguh mengatasi kendala berbahasa Inggris, yaitu kosa kata yang memadai dan gramatika yang mumpuni.

Sembilan Pola Dasar tadi adalah:

a. N+Be+Adj. atau

Noun+Be+Adjective

The students are happy.

b. $\mathrm{N}+\mathrm{Be}+\mathrm{UW}$ atau

Noun+Be+Uniflected

Word

The students are here.

c. $\mathrm{N} 1+\mathrm{Be}+\mathrm{N} 1$ atau Noun 1+Be+Noun 1

Ariandita is Library and Information Studies student.

d. N1+In.V atau Noun 1+Intransitive Verb

Euis smiles.

e. N1+Tr.V+N2 atau Noun 1+Transitive Verb+Noun 2

Danny bought a brandnew $B M W$. 
EduLib, Vol 1, No.1 Mei 2013

f. N1+Tr.V+N2+N3 atau

Noun 1+Transitive

Verb+Noun 2+Noun 3

He bought her a present.

g. $\mathrm{N} 1+\mathrm{Tr} . \mathrm{V}+\mathrm{N} 2+\mathrm{N} 2$ atau

Noun 1+Transitive

Verb+Noun 2+Noun 2

The jury chose Dian Sastro

the loveliest contestant.

h. $\mathrm{N}+\mathrm{LV}+\mathrm{Adj}$.

atau

Noun+Linking Verb+Adj.

Dewi seems satisfied.

i. N1+LV+N1 atau Noun

1+Linking Verb+ Noun 1

My son became a

psychologist.

Beranjak dari ke 9 pola dasar di atas, Kalimat Majemuk 1 (Cd.) dapat dengan mudah dibentuk, yaitu dengan cara menggabungkan misalnya pola dasar 3 dengan menggunakan kata penghubung (and) menjadi seperti ini: Ita Hardianti is a school librarian and Natya Pramudita is a university librarian. Kalimat Majemuk 2

(Cx.) dibentuk dengan menggunakan pola dasar 2 dengan menambahkan klausa kata sifat setelah Noun menjadi seperti ini: The students who are very happy are there. Terakhir, yaitu Kalimat Majemuk 3 (Cdx.) dapat dibentuk dengan cara memasukkan misalnya klausa kata keterangan waktu pada kalimat berpola dasar 5 menjadi seperti ini: Septian was reading a book and Ammy was playing the piano when the lights went out. Bagi pengajar baik dia Guru, Instruktur maupun Dosen, inilah saat yang tepat untuk memainkan peran sebagai badut (a "clown"). Sang pengajar boleh mencoba memicu tawa (terpingkalpingkal) dengan melanjutkan kalimat tadi sambil berujar: .....and what would happen next? Hhmmmm.... only God knows. 
Pembelajar, baik itu Siswa maupun Mahasiswa perlu menyadari bahwa ke 12 kalimat yang dicontohkan tadi adalah kalimat positif, dan tentu saja para pembelajar dapat mengubahnya menjadi kalimat negatif, kalimat interogatif, kalimat negativeinterogatif, dan kalimat perintah.

$$
\text { PoS yang merupakan }
$$

kependekan dari Parts of Speech merupakan bahan "mainan" berikutnya untuk mengembangkan sendiri kosa kata Mahasiwa. PoS utama yang berjumlah 4 (empat) adalah Noun, Verb, Adverb, dan Adjective atau Kata benda, Kata Kerja, Kata Keterangan, dan Kata Sifat. Seorang penulis novel Indonesia yang masyhur karena banyak karya tulisnya diangkat ke layar lebar, pernah menyisipkan PoS ini secara cerdik kedalam salah satu novelnya.

Dia mengungkapkan bahwa untuk pandai berahasa Inggris, "cukup" menguasai keempat PoS tadi. Betul sekali, dan sekarang ketrampilan memainkannyalah yang menjadi kunci keberhasilan menguasai kosa kata. Salah satu contoh kata sebagai objek permainan adalah cantik. Kata ini dapat dijadikan N,V,Adv., dan Adj. yaitu menjadi beauty, beautify, beautifully, dan beautiful. Artinya, materi yang disampaikan di kelas akan dipraktekkan diluar kelas seperti ini misalnya, $B e$ beautiful! (kalimat perintah) dan seterusnya, sampai kalimat berpola yang merupakan kreativitas pembelajar dapat berjumlah ratusan atau bahkan ribuan. 
EduLib, Vol 1, No.1 Mei 2013

Ketika mengekspresikan diri dalam bentuk kalimat pernyataan, pembelajar akan melibatkan dirinya kedalam pemasukan unsur kultur agar tercapai pesan yang dimaksudkannya melalui bahasa sasaran (B.Ing.) kepada penerima pesan. Misalnya, kalimat Rina is actually a truly whistle blower. Untuk memaknai setiap kata didalam kalimat ini, cara harfiah akan menyimpangkan arti, sehingga diperoleh pesan yang berbunyi Rina sebenarnya adalah peniup peluit tulen. Kata whistle dan kata blower diartikan secara harfiah sebagai peluit dan peniup. Padahal, untuk dimengerti oleh bahasa sasaran, kalimat itu seharusnya diartikan sebagai Rina sebenarnya adalah seorang pemukul kentongan tulen. Dari segi kultur, baik peniuip peluit maupun pemukul kentongan dimaksudkan sebagai orang yang suka membeberkan suatu masalah dan mengungkap masalah tersebut sehingga terjadilah semacam peperangan ataupun polemik berkepanjangan. Di Indonesia, pemukul kentongan adalah seseorang yang memberitahu akan adanya bahaya, sehingga masyarakat sekitar akan berbondong-bondong keluar rumah untuk memergoki seorang pencuri, misalnya.

Untuk pemaknaan kultural pada penggunaan ungkapan (idiomatic expression), misalnya, pembelajarannya bisa memakan waktu sangat lama disertai praktek menyatakannya. Misalnya, Berakitrakit ke hulu, berenang-renang ke tepian. Bersakit-sakit dahulu, bersenang-senang kemudian. Akan sulit dicerna oleh bahasa sasaran (B.Ing.) jika dinyatakan sebagai Traveling by raft to an upper reach of a river, going swimming along an edge. Be sick first and have fun afterwards. Selain akan ganjil kedengarannya oleh para penutur asli B.Ing. (native speaker) juga bisa-bisa akan terasa bertele-tele menurut sense (of language) mereka. Didalam kultur mereka ungkapan sepanjang itu sebetulnya mungkin 
bisa pendek saja, kira-kira seperti No pain, no gain. Atau, satu lagi, pemakain frasa corner stone, bukan secara harfiah diartikan sebagai batu pojok, melainkan orang penting. You are the corner stone of this organization, aren't you? Bukan Kamu batu pojok di kantor ini, bukan?, melainkan Anda pejabat penting di sini (kantor, perusahaan, organisasi), bukan? Satu lagi yang terakhir mungkin, yaitu slang. Arti slang, salah satu diantaranya, adalah kata dengan arti "baru" dari kata yang sudah ada tetapi dianggap kurang sopan. Misalnya, kata Chicken! yang artinya adalah Pengecut! dan bukan berarti Ayam! Pengecut didalam B.Ing. normal adalah coward sedangkan chicken didalam Bahasa Indonesia normal adalah ayam. Contoh satu lagi, grand, yang bukan berarti besar atau agung, melainkan US 1,000 (seribu dollar Amerika Serikat). Kamus khusus untuk slang setebal 6 sentimeter (534 halaman) berjudul Concise Dictionary of SLANG and Unconventional English mungkin bisa dikonsultasi untuk maksud pemerkayaan.

3. Teacher Demeanor

Bagi pembelajar, pendekatan oleh pengajar berlabel facilitator ketika menyampaikan materi pada sesi di kelas menjadi titik berangkat menuju keberhasilan berkomunikasi didalam B.Ing. Secercah harapan dan sebersit ekspektasi agar terbebas dari cela ketika mencoba mengekpresikan diri didalam B.Ing. niscaya merupakan sesuatu yang lumrah bagi pembelajar pada umumnya. Teacher Demeanor merupakan pendekatan yang disertai ulasan senyum (sebisa mungkin dengan tulus) dan dilakukan berulang-ulang dengan hati yang legowo penuh pengertian atas berbagai hal yang tidak atau kurang "pas" yang mungkin disodorkan 
EduLib, Vol 1, No.1 Mei 2013

secara tidak sengaja oleh para

pembelajar. Seandainya cara seperti ini tidak membuahkan hasil, sang pengajar bolehboleh saja "berkorban" untuk bermain peran sebagai badut agar nampak lucu dan menggemaskan di mata pembelajar. Tujuannya hanya satu: membuat suasana belajar menjadi hidup dan bersahabat, yang pada gilirannya akan membuat sejuk hati pembelajar yang mungkin akan merasa “aman” karena kekurangannya tertutupi, atau, merasa memperoleh penyelamat muka. Dua kata sarat makna yang berhubungan dengan pendekatan ini adalah freshness dan enthusiasm.

a. Freshness

$$
\begin{aligned}
& \text { "Good morning, class! } \\
& \text { It's always nice to be with } \\
& \text { you again" mungkin cukup } \\
& \text { untuk mempertamai } \\
& \text { ujaran pada sesi di kelas. }
\end{aligned}
$$

Maksudnya adalah upaya untuk mengusir rasa bosan atau penat, dan merupakan sapaan pembuka yang mungkin menyegarkan. Tentu saja masih harus dibarengi ulasan senyum setulus hati, binaran cahaya mata, dan sedikit gestur. Jika ingin langsung mengorbankan diri, sang pengajar boleh saja seketika itu juga bergaya layaknya seorang badut, entah bagaimana caranya. Secara psikologis, para pembelajar sudah dapat merasa aman, terbebas dari intimidasi. Mereka sudah melihat adanya akses ke peluang menuju suasana ringan yang menyenangkan, dan mengenyahkan perasaan ragu-ragu setiap kali akan merespon, bertanya, dan 


bahkan mengomentari
pembuka sesi oleh
pengajar.

b. Enthusiasm

\section{Antusiasme}

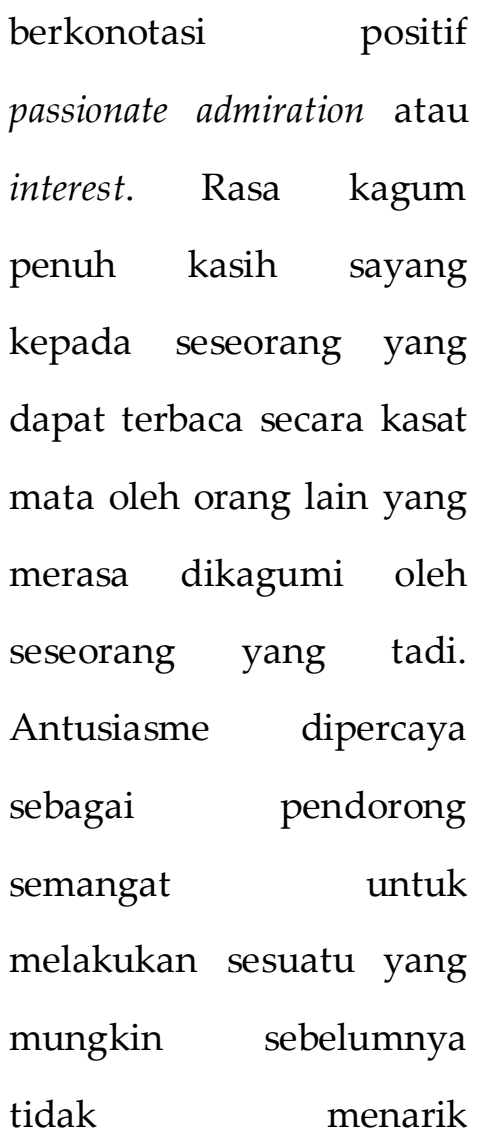

perhatiannya. Minat yang

besar karena sangat menyukai dapat pula menjadi drive dan needs yang pada akhirnya dapat memicu dan memotivasi semangat untuk melakukan sesuatu (baca: belajar). Keinginan belajar ini mempunyai arti melibatkan diri sepenuh hati demi tercapainya tujuan sesuai keinginannya, yang tentu saja dikawal oleh rasa aman sepanjang proses pelibatan diri itu. Motivasi ditimbulkan bukan hanya secara sepihak oleh pembelajar, melainkan juga oleh kawalan pengajar dengan segala daya fasilitasinya.

Kedua karakteristik di atas, segar dan mengundang semangat, merupakan suatu entitas yang dapat berfungsi sebagai salah satu upaya menyiasati suasana belajar berbahasa asing (B.Ing.) sehingga hasil belajar menjadi cukup menjanjikan. Setidaknya 
EduLib, Vol 1, No.1 Mei 2013

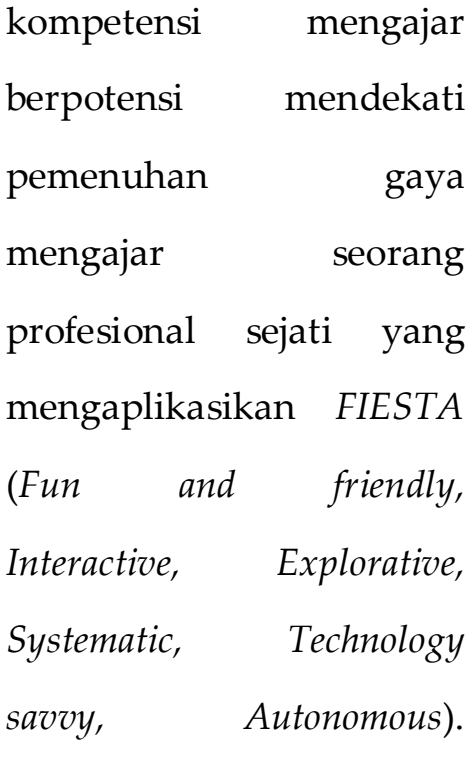

Setidaknya, 2 dari 6 unsur pada FIESTA sudah teraplikasikan. Perpaduan kedua karakteristik tadi dapat menjadikan seorang pengajar memiliki sikap serius, berpengabdian penuh selaku seorang profesional yang percaya akan adanya kemaknaan dan keefektifan mengajar dengan penuh semangat menghargai dan dengan cara menyenangkan seutuhnya.

4. Beban Ganda
Bagi Mahasiswa yang masuk kategori SNED (Students of Non-English Department) seperti misalnya Mahasiswa Program Studi Perpustakaan dan informasi pada Fakultas Ilmu Pendidikan, mengikuti perkuliahan B.Ing. berkemungkinan merupakan sebuah "tantangan" atau, lebih tepat lagi, semacam pembebanan. Apalagi media instruksi yang digunakan pada setiap sesi adalah purely English (kata-kata yang digunakan adalah kata-kata Inggris, intonasinya maupun unsur kulturnya juga Inggris). Nampaknya, selama ini, untuk sekedar memahami materi saja dapat dikatakan fifty-fifty (50\%), sehingga niat untuk sekedar merespon, bertanya, atau mengomentari pemaparan materi kuliah menjadi sesuatu yang agak 


\begin{tabular}{|c|c|}
\hline terkendala. Alat yang & tadi mengakibatkan pemberian \\
\hline sebaiknya digunakan untuk & sanksi pada akhir kegiatan. \\
\hline menghilangkan & Kegagalan \\
\hline terbebani & mengakibatkan \\
\hline Mahasiswa, dan sangat & diberikannya peluang yang \\
\hline memberikan & sama kepada \\
\hline perasaan percaya diri, salah & Mahasiswa lain (ada \\
\hline satunya, adalah SCSA (Student- & kelompok Mahasiswa) untuk \\
\hline Centered Speaking Activity). & memecahkan persoalan yang \\
\hline Didalam kegiatan ini, semua & diwakili oleh kata atau frasa \\
\hline Mahasiswa terlibat dan saling & yang sama yang sebelumnya \\
\hline berkomunikasi & tidak berhasil disebutkan \\
\hline tanpa diintimidasi oleh & dengan benar oleh kelompok \\
\hline pengajar. Intinya, ada suatu & lain yang gagal tadi. Pengajar \\
\hline kata atau frasa yang harus & tidak turut campur tangan \\
\hline dijelaskan menggunakan B.Ing. & untuk urusan gramatika \\
\hline oleh teman-temannya kepada & ataupun pemilihan kata ketika \\
\hline seseorang dari satu kelompok & penjelasan dan penangkapan \\
\hline yang sama, sampai si teman & makna berlangsung selama \\
\hline mendengarkan & satu menit. Bagian terpenting \\
\hline penjelasan tadi didalam satu & dari kegiatan ini adalah \\
\hline kelompok yang sama & menyampaikan pesan tanpa \\
\hline menyebutkan kata atau frasa & khawatir dipersalahkan karena \\
\hline yang disiapkan & keliru memilih kata yang tepat \\
\hline ditayangkan tersembunyi oleh & penggunaan \\
\hline Kegagalan & gramatika yang akurat. \\
\hline butkan & \\
\hline
\end{tabular}


EduLib, Vol 1, No.1 Mei 2013

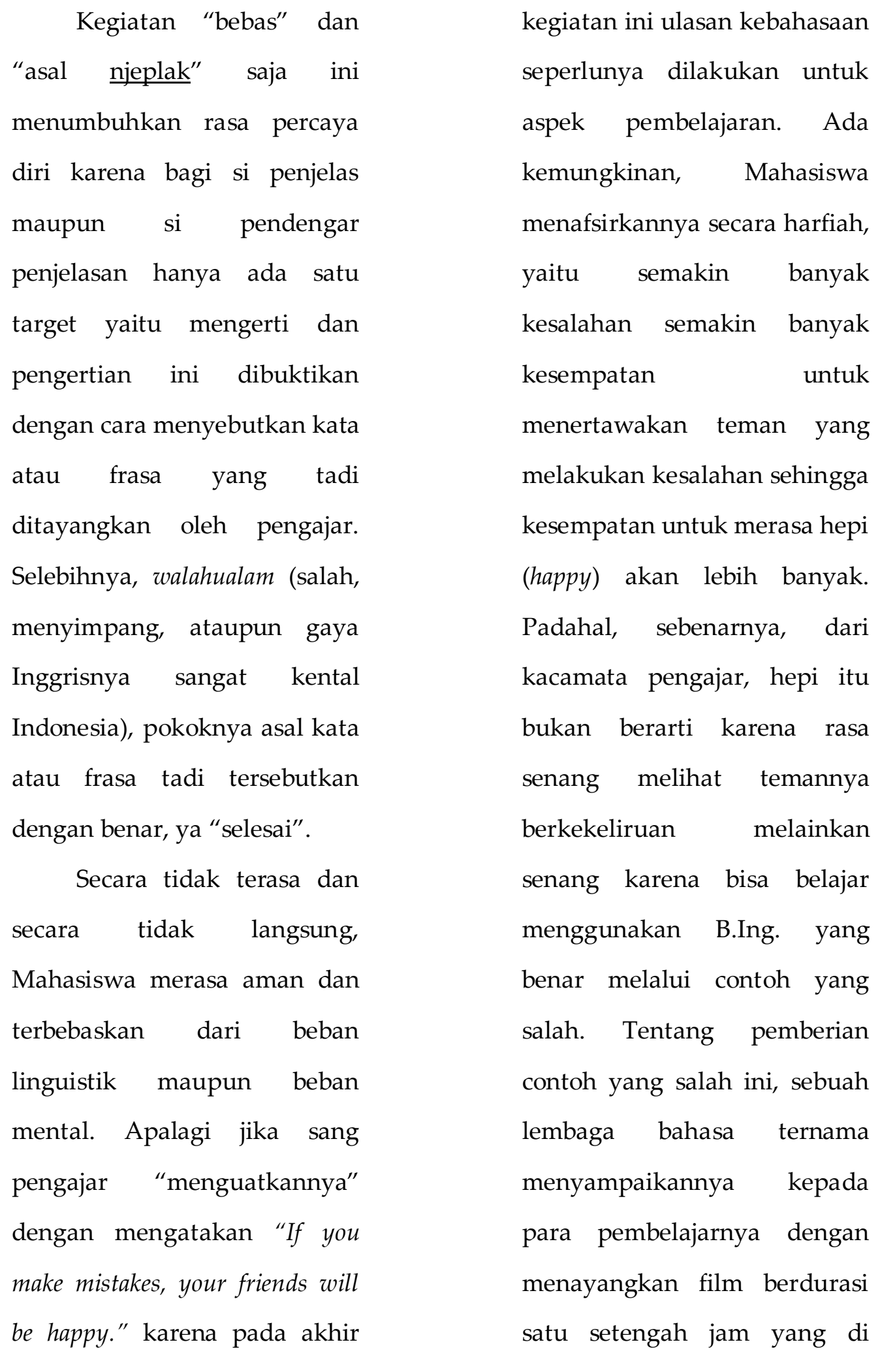




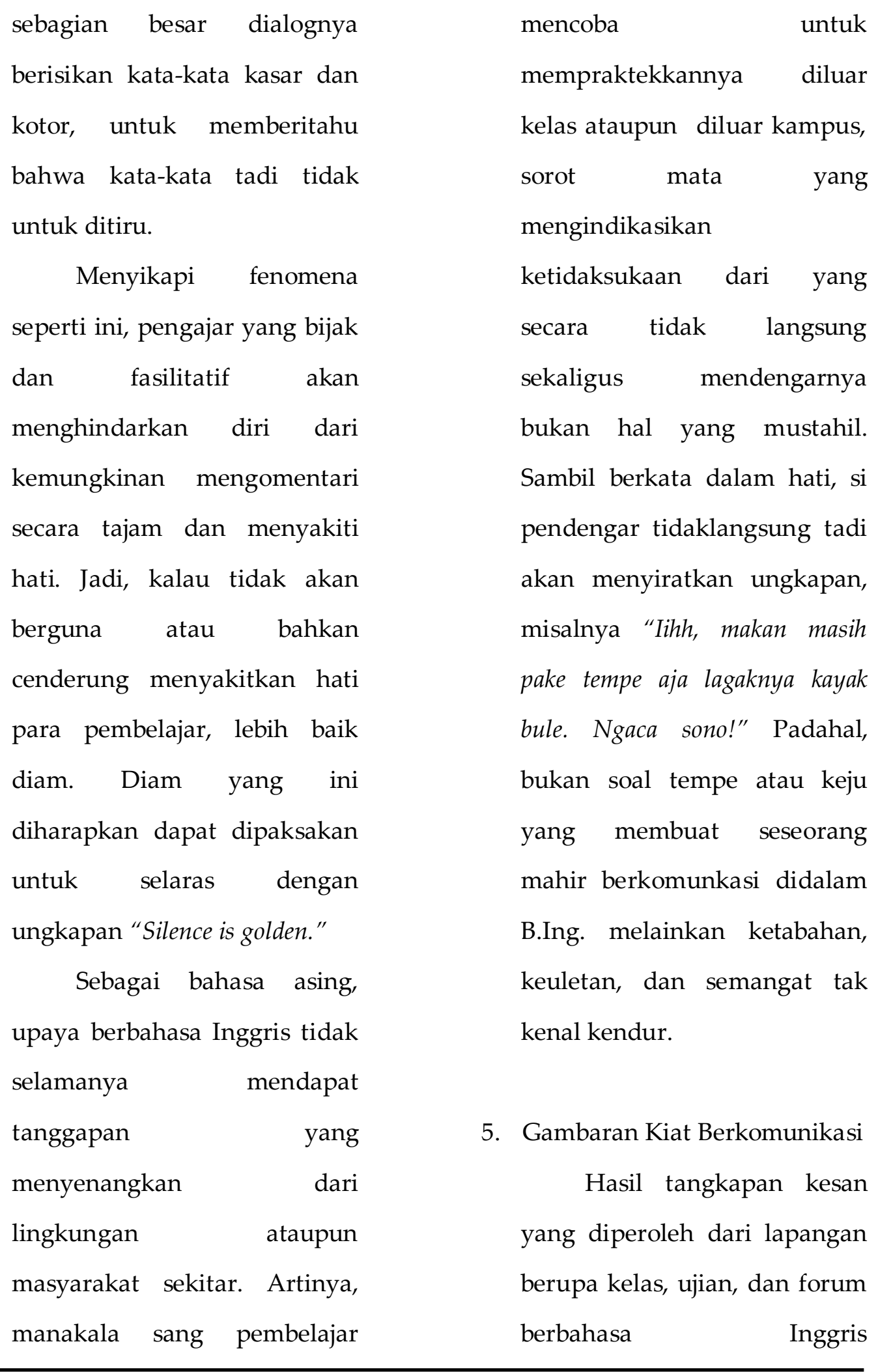


EduLib, Vol 1, No.1 Mei 2013

mengindikasikan bahwa B.Ing.

Mahasiswa berpotensi

menciptakan peluang untuk

mencapai betterment dalam arti

seluas-luasnya. Artinya,

pengasahan dan penuntunan

masih sangat diharapkan

menghasilkan perbaikan

dalam hal Gramatika, Kosa

Kata, dan Kultur (GK3).

Ujaran-ujaran di bawah ini

adalah serba sedikit

percontohan yang diperoleh

dari: kegiatan di kelas atau

berhubungan dengan

penyampaian materi di kelas;

ajang sidang ujian sarjana bagi

SNED; dan forum berhahasa

Inggris dalam bentuk seminar

internasional.

a. Pada Kegiatan Diskusi di

Kelas

$$
\begin{aligned}
& \text { Hi, guys! How are } \\
& \text { you? sebagai ujaran } \\
& \text { seorang } \quad \text { Mahasiswa } \\
& \text { kepada teman-teman } \\
& \text { sekelasnya pada sapan }
\end{aligned}
$$

pembuka diskusi formal

Mahasiswa berbahasa

Inggris yang ditonton

(dinilai, diamati dan

dikomentari Dosen),

tidaklah menjadi masalah.

Apalagi teman-teman

sekelasnya mengerti dan

mau berbagi gugup. Jika

di"bumbui" GK3, ujaran

tadi akan terasa "gurih".

Mahasiswa tadi mungkin

ingin mengatakan Good

morning, my beloved friends.

Shall we say? How are you

doing today? Feeling

well,hopefully.

Beberapa komentar

(7 dari 24) diberikan untuk

memperoleh

gambaransecara jelas

mengenai kegiatan DIMBI

(Diskusi

Ilmiah

Mahasiswa Berbahasa

Inggris). Komentar-

komentar di bawah ini

dicuplik persis seperti 
aslinya dari tulisan tangan

Mahasiswa

Prodi

Perpustakaan

dan

Informasi,

tanpa

menyebutkan nama.

Komentar 1

Dari

namanya

memang keren, wah sekali. Saya pikir tidak di shoot.....lucu dan mengundang lelucon dari temen-teman. Semoga program ini masih bisa dilaksanakan kembali tahun depan untuk adikadik saya dan semoga mereka dapat lebih baik dari kami. Nuhun, Pak!!!

Komentar 2

Menurut pendapat saya mengenai DIMBI sangat membantu dalam menambah vocab Bahasa Inggris. Kegiatan ini sangat menyenangkandan memberikan motivasi untuk terus mengadakan diskusi berbahasa Inggris.

Komentar 3

Kegiatan

ini merupakan awal yang baik yang perlu dipertahankan dan dikembangkan untuk lebih baik di masa yang akan datang. Mungkin kalau bisa dijadikan kegiatan ekstrakurikuler mahasiswa yang menunjang kegiatan akademik. Keep fighting.

\section{Komentar 4}

Menurut saya, mengenai adanya kegiatan Dimbi yang diadakan oleh mata kuliah Pengantar Perpustakaan Digital merupakan suatu kegiatan yang berdampak positif, karena dengan adanya 
EduLib, Vol 1, No.1 Mei 2013

Dimbi tersebut kita

untuk

mengasah

sebagai mahasiswa

kemampuan berbahasa

dituntut untuk berbicara

bahasa Inggris dalam

diskusi ilmiah. Selain itu,

kita juga menjadi tertarik

berkomunikasi dengan

bahasa Inggris setelah

adanya kegiatan Dimbi.

Saya harap kegiatan Dimbi

ini bisa terus

dikembangkan.

Komentar 5

Semoga kedepannya

dimbi akan tetap terus

berjalan bagi adik-adik

kami nantinya. Untuk $\mathrm{Pa}$

doddy tetap menjadi

dosen

yang

menyenangkan bagi kami

serta terus menjadi dosen

yang terbaik. amin.

Komentar 6

DIMBI ini sangat

bagus sekali. Terutama

Inggris terutama $\mathrm{dlm}$ hal

Pronoun Session. Saya suka dan menyenangi kegiatan DIMBI ini, dan saya merasa kangen untuk mengikuti kegiatan DIMBI ini lagi. Sebenarnya setiap mahasiswa telah memiliki kemampuan dlm berbahasa Inggris tinggal kita sendiri

mengembangkan

kemampuan tsb. Kesan saya "AMAZING". I think that's all.

Komentar 7

Menurut saya, DIMBI bagus untuk dilaksanakan, bermanfaat untuk mahasiswa dalam berlatih bahasa Inggris, kalau bias jurusan lain juga mengadakan DIMBI. Komentar video posisi 
pengambilan gambar
kurang tepat sehingga
gambar menjadi seperti
siluet.

Pada komentar 3 dan

komentar 6, mungkin yang dimaksud adalah Keep your spirit high atau paling dekat dengan Keep fighting adalah Keep struggling. Keep fighting lebih merujuk pada ajang kompetitif, yang adalah kurang begitu pas dalam hal ini. Kata amazing berkesan agak berlebihan untuk ukuran kegiatan akademik seperti itu. Mungkin maksudnya adalah Terrific! bukan Amazing. Ekspresi I think that's all baik dan berterima. Namun, ada ekspresi lain yang mungkin dapat menunjukkan kerendahatian sang pengujar seperti misalnya I think that would be about it. Ekspresi Tha's it adalah That (be - is) yang diperlembut dan dipersopan dengan would be sedangkan it akan menjadi lebih aestetik secara kebahasaan dengan ditambahi about didepannya. Artinya, secara rendah hati sejujurnya si pengujar tidak yakin bahwa pendapatnya itu sudah atau belum tepat. Kalau dialihbahasakan kedalam ujaran bernuansa kultur Indonesia, bunyinya menjadi seperti Saya rasa kira-kira cukup demikian dulu mungkin.

b. Pada Kesempatan Bermain Peran sebagai Moderator Tell me the name before you ask a question, OK? sebagai "penggantI" 
EduLib, Vol 1, No.1 Mei 2013

dari It's a $Q$ and $A$ session.

For those of you who are

interested in sharing ideas,

state your name first before

asking a question or giving $a$

response. Make sure the

question is a question. Thank

you.

c. Role Playing

Dialog berikut ini adalah cermin permainan peran dengan topik "Stress at School" yang dimainkan oleh 7 (tujuh) Mahasiswa semester 1 disiplin Ilmu Psikologi. Ada sekitar 7 (tujuh) ketidakpasan yang bisa ditemui pada dialog singkat ini.

Tiara : "Hey how are you?"

Dian : “Not good. I'm feeling so blue today"

Dinda : "Why?"
Dian : "You know what? I love one of our senior"

Hasna : “Oh"

Martina: "My"

Rika : "God"

Tiara : "Are you serious? Who is he?"

Dian : "He is one of comission discipline

Dinda : "Who?"

Wyddie: "Samsudin?"

Hasna : "Darkosim?"

Martina: “Or Jaenab?”

Dian : "No! $\mathrm{He}$ is

FRANDRI"

Tiara : "How can it be?"

Dian : "Based on my opinion he's so delicate. His face so sun bright like a diamond. I confessed my feeling to him last night. But damn it. He refused it. Rika : “Holy cow! I'm sorry to hear that. 
Hasna : "I knew, that was not easy"

Dinda : "If I were you.

I want never ever ever do

that

Dian : "So what should I do than? I'm so stress today.

Wyddie: “I see. Just forget the past. It's gone!

Dian : “I knew. I realized it's so ashamed.

Tiara : "Just take it easy. Everythings gonna be okay.

Martina: "Anyway, we have class so let us go now.

Semua bagian pada diialog di atas ditampilkan persis seperti aslinya dalam tulisan tangan Mahasiswa sebagai skrip dialog. Ketiadaan tanda petik tutup, misalnya, memang demikian tertuliskan. d. Library Tour (LO and BI)

Where are you come from?, I'm very interesting in this library, dan Any question? Masih terkomunikasikan pada kegiatan praktek memandu Mahasiswa asing di perpustakaan melalui Library Tour (Library Orientation and Bibliographic Instruction). Mungkin maksudnya adalah Where are you from? ataupun Where do you come from? Lazimnya, tawaran untuk bertanya dibentuk dalam jamak (plural) agar terkesan umum dan dengan ujaran yang lengkap demi kesantunan: Do you have any questions atau Are there any questions? Bagi Mahasiswa asing yang berasal dari negara berbahasa Inggris (English 
EduLib, Vol 1, No.1 Mei 2013

speaking countries) seperti

Amerika Serikat dan

Kanada, misalnya,

penjelasan teknis tentang penggunaan alat telusur

elektronik untuk akses ke

sumber-sumber informasi

terasa belum pas karena

tidak dilengkapi dengan

diksi (Diction - choice of

words) yang sesuai dan

lazim. I am very interesting

in this library agak

mengundang kejenakaan

karena sang pengujar

merasa menarik dan

menyenangkan kalau

sedang berada di

perpustakaan, sedangkan

diluar perpustakaan dia

tidak menarik lagi.

Maksudnya mungkin I am

very interested in this

library.

Ujaran seperti

berikut ini disampaiakn

oleh Library Tour Leader kepada sekelompok

Mahasiswa asing pada

sebuah perpustakaan

universitas:

OKAY GUYS, THIS

ISMULTIMEDIA ROOM.

There is place for browsing, searching, downloading, and typing. All facilities this room free for user. And this is postgraduate room. We can access in repository upi for see this collection. Now, we will wend second floor. This llibrary have relict deposits. Okay, this is magazine and France Corner. This room will be relaxing for user. And than user can copy essay, thesis, disertasi and other collection in foto copy room. Free from copy can using preservation of collection. emua bagian pada skrip di atas ditampilkan persis seperti aslinya dalam tulisan tangan 
Mahasiswa sebagai skrip

ujaran. Kata wend,

misalnya, memang

demikian tertuliskan.

e. Ujian Sidang Sarjana

Pertanyaan

sederhana pada ujian sidang jenjang S1 seperti

Are you sure, your offer of applying such techniques is promising enough knowing that instructors usually find it difficult to change their own way of giving lectures? mungkin menjadi agak sulit ditangkap maknanya bagi Mahasiswa SNED. Sang penguji sebetulnya hanya ingin menjajal sedikit untuk menyelaraskan antara motto Leading and outstanding university dengan kompetensi riil alumnus kelak di era free trade. Jawaban atas pertanyaan berupa In my experience, teachers want to apply it. agak terasa kentalnya ide Indonesia yang diinggriskan secara tak sengaja. Bukan saja secara gramatika kata it tidak mewakili kata techniques pada pertanyaan, melainkan juga

ketidakbersambungan

antara frasa in my experience dengan teachers want. Maksudnya mungkin adalah As fas I am concerned, the informants of my research are willing to apply them (the techniques). Atau, Yes, I am quite sure. To the best of my knowledge, the respondents show some willingness to apply the techniques.There's no doubt about it, Sir.

f. Q\&A session (Question and Answer session) 
EduLib, Vol 1, No.1 Mei 2013

Agak sukar bagi seorang Keynote Speaker pada Seminar

Internasional memaknai pertanyaan What could you relate between title from outside, grades, and behavior for students? Kalaupun sangat sukar menarik benang merah pertanyaan yang kurang pas, sang Keynote Speaker akan melakukan semacam entertain, dan bukan sepenuhnya jawaban sempurna yang dapat memuaskan sang penanya. Kira-kira, dalam benaknya harus terlintas How would you see any relationships between academic degrees earned from abroad and the behavior of grading among lecturers? sebelum menjawab pertanyaan tadi. Pertanyaan berikut ini pendek tetapi belum pas

Can the best teaching method guarantee the best alumni? Kesenjangan diksi antara proses dengan produk terlalu besar sehingga merepotkan penjawab.

g. Outside The Class

Pada kegiatan Student English Forum Mahasiswa Prodi Perpustakaan dan Informasi yang termasuk berkategori SNED, berbagai cara memperkenalkan diri terdengar. Salah satu diantaranya seperti ini: Hi! I am Vinny. I live here in Bandung. Although my English is not very good, but I join this club to have fun. Ada kemungkinan isi perkenalan tadi merupakan penginggrisan apa adanya, dan sematamata memenuhi serba 
minimal informasi yang

diperlukan tanpa daya pukau bernuansa

kebaruan (sebagai indikasi acquintance). Seperti tidak diniatkan untuk memberi sinyal bahwa percakapan pertama membawa kesan hangat dan mengundang minat untuk berlanjut ke arah yang menyenangkan dalam persahabatan. Vinny akan memerlukan waktu dan kesabaran untuk sampai pada ujaran yang "pas" seperti misalnya $\mathrm{Hi}$, there! My name is Vinny Pindiwiniti but you can call me Vivin. I am interested in joining with this club of conversation just because it looks good the way it is. It also sounds like fun when I see you all together in a harmonious atmosphere chatting, laughing, and having all possible good times. In my spare time, I go swimming. Sometimes I swim alone, all by myself. Yang terakhir ini, sangat menarik untuk disimak dan ditindaklanjuti untuk misalnya suatu persahabatan yang mengasyikkan.

\section{SIMPULAN}

DAN

\section{REKOMENDASI}

Para pembelajar, yang dalam hal ini adalah Mahasiswa, memberikan respon yang positif atas kesediaan pengajar yang berkenan mendekati mereka dengan cara yang menyegarkan dan penuh semangat. "Pengabaian" sementara atas kebakuan kebahasaan telah menghasilkan suatu suasana yang kondusif bagi pembelajaran Bahasa Inggris sebagai bahasa asing. Digantikannya pengabaian tadi oleh sikap jenaka artifisial dari pengajar telah mendorong pembelajar menjadi berani tampil karena tidak beresiko intimidatif. Sangat dianjurkan, oleh 
EduLib, Vol 1, No. 1 Mei 2013

karenanya, untuk senantiasa diupayakan penciptaan suasana yang sedemikian rupa sehingga tujuan akhir pembelajaran dapat secara "tidak sengaja" tercapai: inisiatif tampil berbicara dengan rasa percaya diri dan cukup komunikatif. Khususnya Mahasiwa Prodi Perpustakaan dan Informasi, suatu ketika kelak dapat menghasilkan sebuah karya yang apabila dikumandangkan, akan setara dengan "This piece of work is dedicated to all librarians who have turned a child on to reading, taught a teacher a new technology skill, and made the world a better place by improving the effectiveness of their schools with great library programs. And of course, to the librarians who do these things everyday" (sumber: Doug Johnson, 2013. The Indispensable Libraraian).

\section{SUMBER RUJUKAN}

Alexander, G. (1989). Developing Skills: understanding, speaking, reading, and writing. London: Oxford University Press.
Allen, WS. (1974). Living English Structures. 5th ed. Aylesbury, Bucks: Hazel Watson \& Viney Ltd.

Allyn, BOP. (2013). Culture and Language. Bacon: Prentice Hall.

Cakir, I. (2006). Developing Cultural Awareness in Foreign Language Teaching. Turkish Online journal of Distance Education - TOIDE. Vol.7 \#3.

Eastwood, J. And Ronald Mackin. (1982). A Basic English Grammar. London: Oxford University Press.

Fodor, JA. et.al. (1974). The Psychology of Language. New York: McGraw-Hill Book Company. FM, G. (2009). Start Speaking English Today: superbook of conversation. Jakarta: Transmedia Pustaka.

Macau, CM. (2003). Through Translation: considering multiple intellegencies. Cambridge: University Press. 
Franklin, HB. et.al. (1990). Vocabulary in Context. Jakarta: Binarupa Aksara.

Hidayat, AA. (2009). Filsafat bahasa: mengungkap hakikat bahasa, makna dan tanda. Bandung: Remaja Rosdakarya.

Jones, D. (1978). The Pronunciation of English. $4^{\text {th }}$ ed. Cambridge: University Press.

Macau, CM. (2003). Through Translation: considering multiple intellegencies. London: Oxford University Press.

Moore, J. (1982). Reading and Thinking in English: discourse in action. London: Oxford University Press.

Munoz, BJ. (2005). Learning through Humor: using humorous resources in the teaching of foreign languages. Trinity School. The ATIS Bulletin.

Nation, ISP. (2001). Learning Vocabulary in Another Language. Cambridge: University Press.
Parsons, J. (2013). Classroom Strategies for Teaching Language. Available at Archive Education. Suite101.com/a/classroomstrategies-for-teaching-language. Rusmono, D. (2010). An Investigation of Librarian's Translating Ability. Disertasi yang belum dipublikasikan. Prodi Pend. Bhs. Inggris. Sekolah Pascasarjana Universitas Pendidikan Indonesia 